\title{
A VISÃO SOBRE CIÊNCIA NAS REVISTAS SUPERINTERESSANTE E QUERO SABER: ESTUDO COMPARATIVO ENTRE BRASIL E PORTUGAL
}

\section{THE VIEW ON SCIENCE IN THE MAGAZINES SUPERINTERESSANTE AND QUERO SABER: COMPARATIVE STUDY BETWEEN BRAZIL AND PORTUGAL}

\author{
CARVALHO, Igor Leandro Alves de ${ }^{1}$ \\ ROCHA, Marcelo Borges ${ }^{2}$ \\ COSTA, Pedro Miguel Marques $\mathrm{da}^{3}$
}

\begin{abstract}
RESUMO
Esta pesquisa investigou como duas revistas apresentam ao público as atividades características da construção do conhecimento científico acerca da temática Aquecimento Global, inferindo que tipo de visão sobre a ciência as revistas propagam. A partir do mapeamento dos artigos no período 2012-2017, apoiado nas técnicas de Análise de Conteúdo, foi analisado se os artigos apresentam (e de que maneira) os procedimentos, materiais e/ou instrumentos que são cotidianos na construção do conhecimento científico, bem como, as discussões no âmbito das ideias que acontecem na comunidade científica. Poucos artigos, em ambas as revistas, apresentam elementos que caracterizam a dinâmica científica ao leitor, tanto no âmbito dos procedimentos, quanto no âmbito das ideias. Em relação aos procedimentos internos da Ciência, o comportamento das revistas se distancia, pois a Superinteressante explora melhor esse ponto. Com relação ao funcionamento, as revistas se aproximam em relação a não ter interesse em explorar esse ponto apresentando o contexto ao leitor. Concluiu-se que distanciar do público as circunstâncias que cercam a construção do saber científico corrobora para uma visão distorcida de ciência.
\end{abstract}

PaLAVRAS-CHAVES: divulgação científica; mídia impressa; aquecimento global; revistas de divulgação científica; sobre ciência.

\footnotetext{
${ }^{1}$ Doutorando em Ciência, Tecnologia e Educação do Centro Federal de Educação Tecnológica Celso Suckow da Fonseca (CEFET/RJ). Docente na Secretaria de Estado de Educação do Rio de Janeiro (SEEDUC/RJ). Rio de Janeiro, RJ, Brasil. ORCID: http://orcid.org/0000-0002-4178-4660 e-mail: igor.leandro@yahoo.com.br

2 Doutor em Ciências Biológicas pela Universidade Federal do Rio de Janeiro (UFRJ). Docente do Programa de Pós-graduação em Ciência, Tecnologia e Educação no Centro Federal de Educação Tecnológica Celso Suckow da Fonseca (CEFET/RJ). Rio de Janeiro, RJ, Brasil. ORCID: http://orcid.org/0000-0003-4472-7423 e-mail: rochamarcelo36@yahoo.com.br

${ }^{3}$ Mestre em Ensino de Física e de Química pela Universidade do Porto. Universidade de Lisboa. Lisboa, Portugal. ORCID: http://orcid.org/0000-0001-8839-2878 e-mail: pedro mmco@hotmail.com
} 


\section{ABSTRACT}

This research investigated how two magazines present to the public activities regarding construction of scientific knowledge on Global Warming, inferring which view on science those magazines propagate. Based on survey of articles published in 2012-2017 and supported by techniques of content analysis, one analyzed whether the articles show (and in what way) procedures, materials and/or instruments that are current for the construction of knowledge, as well as discussions of ideas in the scientific community. In both journals few articles show elements that characterize a scientific dynamic to the reader, in the scope of its procedures as well as of its ideas. Concerning internal scientific procedures, the magazines are quite apart, since Superinteressante better explores this aspect. In relation to their functioning, the magazines approach each other, as they are not interested in exploring this point presenting the context to the reader. It was concluded that by pulling away from the public circumstances regarding construction of scientific knowledge adds to a distorted view of science.

KeYWORDS: scientific dissemination; printed media; global warming; science communication journals; about science.

\section{INTRODUÇÃO}

Torna-se cada vez mais evidente a forte influência dos conhecimentos científicos em nosso cotidiano, que vai desde a tomada de decisões do que comprar até a forma desejável para descartar nossos resíduos. Entretanto, obter um grande número de informações apenas, não garante a reflexão sobre os impactos recebidos pela sociedade tecnocrática, nem tão pouco, o envolvimento sobre os rumos da coletividade. Como defendem Praia, Gil-Perez e Vilches (2007), não é o nível elevado do conhecimento nem a grande quantidade de informações que vão garantir ao cidadão a capacidade de participação na tomada de decisões, mas, o mínimo de conhecimentos que torne possível o entendimento das ações, problemas, opções, consequências.

De acordo com Valério e Bazzo (2006), uma visão crítica da ciência e da tecnologia pode ser obtida por meio das atividades de divulgação e educação científica. Eles consideram a divulgação da ciência como um acervo de práticas no campo da comunicação, atuando na exposição pública dos conhecimentos através de diversificados meios.

De maneira geral, a Divulgação Científica (DC) está sempre ligada ao saber compartilhado, demonstrando os processos de construção do conhecimento, resultados de pesquisa, temas controversos da ciência, entre outros. A fim de posicionamento, entendemos a DC como o compartilhamento do conhecimento científico, através de variadas formas de veiculação, tendo em seu mais valioso propósito promover a participação dos cidadãos na discussão dos assuntos científicos, tecnológicos, sociais e ambientais. 
Nesse saber compartilhado - tomado aqui como essência da DC - diferentes aspectos podem ser observados. Albagli (1996) aponta que dependendo da ênfase dada aos objetivos e aspectos, as possiblidades de utilização da DC são amplas, e essa amplitude se estende em relação ao público-alvo, pois o público está ligado à atividade. A autora acrescenta potencialidades que as atividades de divulgação científica possuem: de servir como instrumento promotor de "maior consciência social sobre a atividade científica" (ALBAGLI, 1996, p. 402), ou instrumento de "mistificação da opinião pública sobre a ciência" (ALBAGLI, 1996, p. 402).

Também sobre as possibilidades de utilização da DC, Lima e Giordan (2017) inferem que diversificados propósitos podem ser desempenhados pela DC, e estes estão fortemente inseridos nas práticas docentes em sala de aula.

Rocha (2017) sinaliza que a DC busca, em seus diversos formatos, informar o leitor justamente sobre os assuntos que permeiam a sociedade. Isso faz com que os indivíduos estabeleçam uma relação mais estreita com a ciência e a tecnologia, já que, as informações recebidas pela sociedade fazem parte da dinâmica social, interferindo na maneira como o sujeito percebe o mundo e o modifica.

As atividades de DC possuem, então, uma perspectiva sociocultural. A maneira como a comunicação ao público não especializado acontece e $o$ que é comunicado influencia no desenvolvimento da reflexão crítica e participação da sociedade, ou, no distanciamento entre os especialistas e o público não especializado reforçando uma visão ingênua da construção do conhecimento científico. Fraga e Rosa (2015) colocam que a ciência está consolidada na organização da sociedade e no cotidiano social, mas nem sempre é fácil estabelecer a relação entre o conhecimento produzido nas pesquisas científicas e nossas atitudes diárias.

Justamente nessa perspectiva sociocultural, Pechula (2007) coloca que os grandes veículos de comunicação de massa (televisão, jornais e revistas) divulgam as grandes descobertas e avanços tecnológicos, instigando um imaginário de que cabe à ciência a resolução dos problemas, sobretudo, daqueles que envolvem a sobrevivência humana e do planeta. Esse imaginário social - engrenagem que permite a compreensão das atitudes dos indivíduos na busca por ideais a serem seguidos - leva em consideração as ideias conhecidas e compartilhadas. Portanto, a divulgação do conhecimento através de uma informação acabada, pronta, fechada para a possibilidade de discussão, que não demonstra o processo de construção desse conhecimento (divergência de ideias, procedimentos de coleta e análise de dados, materiais utilizados, validação, entre outros), pode influenciar nesse imaginário citado pela autora.

Em contrapartida a essa visão acerca da comunicação em massa, Gadea et al. (2017) apontam para a utilidade destes veículos em combater o desinteresse (principalmente pelos jovens) nos estudos científicos causado pela apresentação de conhecimentos de maneira descontextualizada. Esses autores acreditam que a mídia pode ser um recurso muito útil quando veicula uma ciência e uma tecnologia 
socialmente contextualizada, pois isso potencializa o desenvolvimento de atitudes e habilidades críticas.

Nesse contexto de relevância dos meios de comunicação, a mídia impressa, sobretudo as revistas especializadas em divulgação da ciência, recebem destaque pelas características que possuem e as diferencia dos demais veículos. As revistas de divulgação da ciência são vistas por Carvalho (2011) como o meio mais propício à atualização e formação permanente da pessoa, justificando-se pela possibilidade de aprofundamento na análise. Dias e Almeida (2009) destacam o linguajar adotado pelas revistas como podendo apresentar maior aprofundamento dos conteúdos abordados. Grillo (2013) também sinaliza para a possibilidade de aprofundamento dos temas científicos nas revistas, mencionado a periodicidade e as instâncias de produção, circulação e recepção das revistas. Além disso, a estética (gráfico, infográfico, ilustrações e qualidade gráfica) imprime uma forte marca do entretenimento (Moraes, 2007), maior riqueza de figuras de linguagem e de tipos textuais, entre outras características que colocam as revistas em vantagem frente a outros meios de divulgação.

O problema do desinteresse (quando não abandono) por parte dos jovens estudantes já vem sendo apontado por Praia, Gil-Perez e Vilches (2007), como sendo gerado por visões empobrecidas e distorcidas da ciência que são construídas pelo ensino científico reduzido à apresentação de conhecimento pronto. Se entre os especialistas (formados e em formação), uma visão pobre, distorcida, ingênua da ciência pode gerar desprezo, o mesmo pode acontecer entre o público não especialista.

Em Relação à visão sobre a ciência, Moura (2014) traz um panorama de pesquisas nacionais e internacionais que têm o propósito de fomentar não somente 0 ensino de ciência, mas também sobre ciência. Em seu trabalho, o autor coloca que o entendimento sobre ciência passa pela compreensão do que é denominado natureza da Ciência (NdC). Mesmo sendo um termo polissêmico, NdC pode ser entendida como o conjunto de elementos que tratam do contexto da produção do conhecimento científico, envolvendo a sua construção, estabelecimento e organização, sendo influenciado por questões internas (por exemplo, o método científico) e externas (por exemplo, a influência elementos culturais na aceitação de uma ideia científica). De acordo com Moura (2014), é necessário um esforço em incorporar a NdC no ensino, sobretudo, para que as percepções distorcidas e simplistas sobre ciência sejam trabalhadas, problematizadas e superadas.

De fato, a superação de uma visão distorcida, ingênua, distante da realidade científica, inadequada sobre ciência, passa pela compreensão mais profunda do funcionamento da ciência, de como o conhecimento é produzido, validado e comunicado, assim como a própria natureza desse conhecimento. Nas palavras de Martins (2015, p. 730), saber sobre ciência nesse contexto representa "uma superação de visões de senso comum acerca desse empreendimento humano, contextualizado histórica e socialmente, chamado ciência". 
Uma visão messiânica da ciência, isto é, de que a resolução de todos os problemas se dá pelo conhecimento científico, e este é concebido de maneira infalível, unânime e sem divergência, distancia-se a passos largos da maneira como o conhecimento científico de fato se constrói. Se a percepção distante da realidade pode ser transmitida até mesmo dentro da comunidade acadêmica no ensino de ciências (GIL PÉREZ et al., 2001; MCCOMAS, 1998; AZEVEDO; SCARPA, 2017), certamente ela também é transmitida para o público não especialista.

Dentro dessa discussão acerca do acesso ao conhecimento científico, chamamos a atenção para as questões ambientais, que cada vez mais têm sido tema de debate em diversos setores da sociedade. Temas como aquecimento global, biodiversidade, sustentabilidade, ambientalismo, cidadania ambiental e mudanças climáticas são alguns exemplos dessas discussões (SULAIMAN, 2011).

Desta forma, percebemos que as questões ambientais permeiam nosso cotidiano, seja na educação, seja nos veículos midiáticos. As mudanças climáticas possuem, em especial, todo um contexto de controvérsias que oferece a possibilidade de exploração do tema pelos meios de comunicação em massa e pelos veículos de divulgação científica (CARVALHO; ROCHA, 2018).

Esse contexto de controvérsias muito se deu pelo fato do clima ter atraído a atenção de múltiplos atores que demandam posicionamento e recomendações de políticas públicas contraditórias, fazendo com que o conhecimento científico sobre tudo que envolve o clima seja relevante na tomada de decisão e avaliação de risco (LEITE, 2015).

Com relação aos temas ambientais, especificamente o aquecimento global, Carneiro e Toniolo (2012, p. 370) sinalizam para o papel fundamental que os meios de comunicação assumem no esclarecimento público de tais questões, "na medida em que podem veicular e/ou omitir determinados tópicos".

Loose e Girardi (2009), em uma visão mais otimista, destacam as revistas de temática ambiental pela capacidade de produzir múltiplos enfoques e pela profundidade com que normalmente explicam e compreendem as questões relacionadas ao meio ambiente.

Diante disso, é importante reconhecer que a mídia impressa cumpre como um dos papéis sociais a transmissão de informações, contudo esse papel não é neutro, mas imbuído de valores e poder, legitimado socialmente e qualificando crenças, valores e atitudes (MONERAT; ROCHA, 2017).

Nesse contexto, perante a relevância da DC em aproximar o público não especialista de questões científicas e de contribuir para a aproximação da realidade do indivíduo ao que é discutido na coletividade, investigar como os textos de DC veiculados por revistas apresentam (ou não) os processos inerentes à construção do conhecimento científico para o público geral torna-se cada vez mais importante. 
Sendo assim, este estudo teve o objetivo de investigar como as revistas Superinteressante e Quero Saber apresentam ao público as atividades características da construção do conhecimento científico acerca da temática Aquecimento Global, inferindo que tipo de visão sobre a ciência as revistas propagam.

\section{Metodologia}

Este trabalho configura-se como uma pesquisa qualitativa ancorada na análise documental (LÜDKE; ANDRÉ, 1986; GODOY, 1995). É um recorte de uma pesquisa de dissertação que investigou o comportamento da DC no Brasil e em Portugal através das revistas de DC, acerca do tema Aquecimento Global.

A escolha das revistas Superinteressante e Quero Saber é justificada pelas características comuns encontradas no universo das revistas de DC, que as duas possuem: periodicidade de publicação (as duas revistas publicam mensalmente), ampla abrangência ao público (oferecem ao público o acesso à reportagens/artigos nos sites, são vendidas nos mais diversos locais físicos e também oferecem venda de seus exemplares através da internet), são publicações de editoras importantes (Editora Abril e Editora Goody) em seu país e possuem perfil semelhante a primeira vista. Além disso, dentro da classificação proposta por Gomes (2000) de distinguir revistas de DC em: revistas híbridas e revistas jornalísticas; tanto a Superinteressante quanto a Quero Saber são classificadas como revistas jornalísticas (textos com autoria exclusiva de jornalistas). Isso oferece possibilidades de discussão sobre a abordagem do tema e suas consequências no contexto social e educacional, na perspectiva da efetividade da interlocução desses profissionais na aproximação entre os públicos envolvidos.

Vale ressaltar que conseguimos o material da revista Quero Saber com a Universidade do Minho (Portugal), em uma tentativa bem sucedida de uma parceria, o que condicionou diretamente o recorte temporal deste estudo, bem como, a possiblidade de contribuir para a discussão sobre a relevância da mídia impressa (em especial as revistas de DC) em seus diversos contextos culturais, ultrapassando as fronteiras brasileiras.

Foram verificadas todas as edições no período de 2012 a 2017, no intuito de mapear os artigos que, de alguma maneira (dando centralidade, indiretamente, utilizando como partida para construção do texto, utilizando para contextualizar argumentos, etc.), tratam do tema Aquecimento Global. O método da Análise de Conteúdo, que segundo Bardin (2002, p. 38) é um "conjunto de técnicas de análise das comunicações que utiliza procedimentos sistemáticos e objetivos de descrição do conteúdo das mensagens", foi escolhido para analisar os textos. Com o intuito de compreender criticamente o sentido (oculto ou manifesto) das comunicações através da análise, descrição e interpretação das mensagens/enunciados dos textos, seguimos uma das possibilidades de categorização - uma marca desse método - propostas por Bardin (2002): a categorização a priori, decorrida do funcionamento direto dos pressupostos teóricos e hipotéticos. 
A partir da leitura dos artigos, apoiando-se nos pressupostos da Análise de Conteúdo, foram criadas duas categorias de análise, a saber: Procedimentos internos da ciência, e, Funcionamento institucional da ciência.

$\mathrm{Na}$ categoria Procedimentos internos da ciência, o que se investiga é se o texto apresenta ao público os procedimentos, materiais e/ou instrumentos que são cotidianos na construção do conhecimento científico. Tais como: a elaboração, aplicação e adequação de modelos, os caminhos tomados para se chegar aos resultados obtidos pela fonte da informação, o papel da experimentação, os procedimentos de análise e inferência dos dados, entre outros. Esses procedimentos aqui investigados não representam etapas clássicas do fazer científico (por exemplo, delimitação de problema, testes, teorias, métodos), mas sim, elementos materiais que evidenciem o trabalho dinâmico da ciência na construção do conhecimento científico.

$\mathrm{Na}$ categoria Funcionamento institucional da ciência, o que se investiga é se o texto apresenta ao seu leitor características inerentes ao funcionamento institucional da ciência, isto é, se as controvérsias científicas, a diversidade de ideias, os conflitos de pesquisadores, a relação entre o processo da ciência e seu produto, são explicitados no decorrer do texto. É aqui que buscamos observar se as discussões no âmbito das ideias que acontecem na comunidade científica são apresentadas ao leitor.

Em outras palavras, a análise atentou para palavras, termos, sentenças e expressões que representam processos de construção do conhecimento que está sendo (ou não) divulgado nos textos da revista.

\section{Resultados e discussão}

Foram encontrados vinte e quatro (24) textos, nove (9) da Superinteressante (Quadro 1) e quinze (15) da Quero Saber (Quadro 2), que tratam do tema Aquecimento Global. De maneira a contribuir para o melhor entendimento das informações, optamos por apresentar os resultados por categoria. De maneira a oferecer elementos de comparação entre as revistas, optamos por apresentar em cada categoria, os resultados das revistas em paralelo.

QUADRO 1- INFORMAÇÕES DOS ARTIGOS DA REVISTA SUPERINTERESSANTE

\begin{tabular}{|c|c|c|}
\hline Código & Título & Publicação \\
\hline SUP01 & O futuro - como ele será: ambiente & Agosto/2012 \\
\hline SUP02 & $\begin{array}{c}\text { Experiência para tentar reverter o } \\
\text { aquecimento global pode resultar em } \\
\text { catástrofe }\end{array}$ & Março/2013 \\
\hline SUP03 & $\begin{array}{c}\text { Cientistas criam bactéria que come CO2 } \\
\text { do ar }\end{array}$ & Maio/2013 \\
\hline SUP04 & $\begin{array}{c}\text { Superbolha pode acelerar aquecimento } \\
\text { global }\end{array}$ & Outubro/2013 \\
\hline SUP05 & Teremos cada vez mais tornados & Novembro/2013 \\
\hline
\end{tabular}




\begin{tabular}{|c|c|c|}
\hline SUP06 & Clima extremo & Março/2014 \\
\hline SUP07 & $\begin{array}{c}\text { Superplanta faz mais } \\
\text { Fotossíntese }\end{array}$ & Maio/2014 \\
\hline SUP08 & $\begin{array}{c}\text { Aquecimento global afeta a } \\
\text { produtividade dos países }\end{array}$ & Dezembro/2015 \\
\hline SUP09 & Máquina transforma CO2 em comida & Outubro/2017 \\
\hline
\end{tabular}

Fonte: Elaboração própria

QUADRO 2 - INFORMAÇõES DOS ARTIGOS DA REVISTA QUERO SABER

\begin{tabular}{|c|c|c|}
\hline Código & Título & Publicação \\
\hline QS01 & Controlar o tempo & Março/2014 \\
\hline $\boldsymbol{Q S 0 2}$ & Podemos travar o aquecimento global? & Agosto/2016 \\
\hline $\boldsymbol{Q S 0 3}$ & Poluição do ar & Agosto/2016 \\
\hline $\boldsymbol{Q S 0 4}$ & Alterações climáticas: toda a verdade & Agosto/2017 \\
\hline $\boldsymbol{Q S 0 5}$ & $\begin{array}{c}\text { "Não há aquecimento global porque o } \\
\text { tempo tem estado mais frio" }\end{array}$ & Agosto/2017 \\
\hline $\boldsymbol{Q S 0 6}$ & $\begin{array}{c}\text { "Os cientistas discordam sobre as } \\
\text { alterações climáticas" }\end{array}$ & Agosto/2017 \\
\hline $\boldsymbol{Q S 0 7}$ & $\begin{array}{c}\text { "Alterações climáticas que hoje vemos } \\
\text { são totalmente naturais" }\end{array}$ & Agosto/2017 \\
\hline $\boldsymbol{Q S 0 8}$ & $\begin{array}{c}\text { "O tempo extremo é um efeito direto } \\
\text { das mudanças climáticas". }\end{array}$ & Agosto/2017 \\
\hline $\boldsymbol{Q S 0 9}$ & "O CO2 não é o problema, é o metano" & Agosto/2017 \\
\hline $\boldsymbol{Q S 1 0}$ & "Os animais podem sempre adaptar-se" & Agosto/2017 \\
\hline $\boldsymbol{Q S 1 1}$ & $\begin{array}{c}\text { "Mais CO2 é bom porque as plantas } \\
\text { precisam dele" }\end{array}$ & Agosto/2017 \\
\hline $\boldsymbol{Q S 1 2}$ & "Tudo não passa de uma conspiração" & Agosto/2017 \\
\hline $\boldsymbol{Q S 1 3}$ & "Alguns graus não farão diferença" & Agosto/2017 \\
\hline $\boldsymbol{Q S 1 4}$ & "Nada podemos fazer para travar as \\
mudanças" & Agosto/2017 \\
\hline $\boldsymbol{Q S 1 5}$ & $\begin{array}{c}\text { "As mudanças climáticas são geradas } \\
\text { pelo Sol" }\end{array}$ & Agosto/2017 \\
\hline
\end{tabular}

Fonte: Elaboração própria

Ao observar o número de artigos no período, a Quero Saber apresenta maior número de textos. Isso se dá pela edição de agosto de 2017 que traz como proposta, expressa no título da edição, discutir afirmações sobre o tema mudanças climáticas consideradas mitos pela revista: "Desfazemos 11 mitos comuns sobre as mudanças meteorológicas que ameaçam o planeta". Nessa edição, é publicado um artigo para cada mito citado pela revista, e por isso, os onze (11) textos não são extensos e tratam especificamente do assunto apresentado de forma direta e sucinta. Embora a Superinteressante tenha menos artigos publicados, sua regularidade de publicação no período é melhor. A revista publicou textos que tratam do Aquecimento Global em, pelo menos, uma edição por ano (com exceção do ano 2016). Isso nos leva a alguns 
questionamentos para investigações futuras: (i) o tema é mais interessante midiaticamente aqui no Brasil do que em Portugal? (ii) as outras revistas portuguesas se comportam da mesma forma que a revista Quero Saber? (iii) será que o tema Aquecimento Global recebe, pelas revistas de DC em regiões diferentes, tratamento distinto?

\section{Procedimentos internos da CiÊNCIA}

O comportamento das revistas nessa categoria tem momentos de aproximação e momentos de distanciamento. Enquanto a revista Superinteressante possui, apenas três artigos que não apresentam (SUPO2, SUPO4 e SUPO9) algum tipo de informação que possa ser classificada como um procedimento científico ao seu leitor, a revista Quero Saber possui a maioria dos seus artigos (QSO2, QSO3, QSO5, QSO6, QSO8, QSO9, QS10, QS12, QS13, QS14 e QS15) sem nenhuma informação que retrate um procedimento, material ou instrumento que caracterize o processo de construção do conhecimento científico.

Na Superinteressante, os artigos SUP01, SUP03, SUP05, SUP06, SUP07 e SUP08 apresentam algum tipo de informação nesse contexto, contudo não se observa discussão dessa informação. Igualmente, na Quero Saber não se observa discussão da informação em seus artigos (QS01, QSO4 e QS11). Somente no artigo QS07 existe uma tímida discussão.

Existe uma característica comum aos artigos que apresentam procedimentos internos da ciência: os procedimentos são colocados e auxiliam no contexto do artigo, na construção dos argumentos, são citados em sua maioria para credibilizar o artigo, isto é, os procedimentos servem para trazer relevância, respaldo aos fatos apresentados, justificar e reforçar a ideia do texto.

Por exemplo, os artigos SUP06, SUP07 e SUP08 foram os que mencionaram de forma mais simplista, mas com essa característica. O SUPO6 utiliza a expressão "modelos climáticos" para respaldar uma afirmação feita por especialistas, sem discutir ou apontar desdobramentos a partir da informação: "Pode parecer paradoxal, mas os modelos climáticos explicam como o aumento médio de temperatura da Terra leva a invernos mais rigorosos". Da mesma forma, o artigo SUP08 utiliza da expressão "modelos criados pelos pesquisadores" no intuito de justificar o argumento principal do texto que é a interferência do aquecimento global na produtividade dos países. 0 SUPO7 avança um mais, pois apresenta informação sobre o trabalho realizado pelos cientistas: "Os cientistas injetaram nanopartículas de dióxido de cério (um metal raro) nos cloroplastos". Além disso, aponta uma consequência prática: "Essas partículas de metal facilitaram o fluxo de elétrons dentro do vegetal, acelerando a fotossíntese".

Apresentando essa mesma característica comum, o texto QSO1 apresenta informações que retratam procedimentos e o texto deixa claro que a maioria dos procedimentos "permanece em laboratório". O texto começa informando sobre um 
procedimento relacionado à inseminação de nuvens, "(...) depois de operários terem disparado foguetes com pequenas bolas de iodeto de prata para nuvens carregadas"; passa para a inseminação de montanhas apresentando como o projeto se desenvolve, "modelos informáticos avançados e instrumentos de radar que conseguem 'ver' para dentro das nuvens"; apresenta outro procedimento relacionado à inseminação de nuvens, "(...) usa um radar numa aeronave e instrumentos no solo"; e por fim, apresenta um procedimento de teste realizado (e posteriormente abandonado) por um projeto de pesquisa que consiste em "bombear água a $1 \mathrm{~km}$ na vertical através de um tubo preso a um balão de hélio, para testar a injeção de aerossóis de sulfato através de uma mangueira gigante $20 \mathrm{~km}$ acima do solo". Os procedimentos são colocados de maneira a enriquecer a construção dos argumentos, mas não há discussão sobre eles.

Nos artigos QSO4, QSO7e QS11 é possível observar um mesmo posicionamento de creditar um caráter infalível à ciência e/ou aos pesquisadores.

O artigo QS04 que apresenta diversos dados científicos sem mencionar como a comunidade científica obteve as informações, dedica um trecho no final do artigo para demonstrar de que maneira governos e cientistas tentam agir para minimizar os riscos das mudanças climáticas. $\mathrm{O}$ texto coloca que os dados responsáveis por auxiliar os governos e comunidade científica são adquiridos por satélites "apontados à Terra, captando fotos e efetuando medições". Coloca o procedimento e a atuação dos cientistas com grande eficácia e indefectível. Isso pode ser percebido em trechos como "cientistas estão a trabalhar para monitorar o planeta e modelar os possíveis efeitos das mudanças climáticas", também em "investigadores em terra conduzem estudos para descobrir", e, "Com base nos conselhos dos especialistas da área, tentam mitigar os riscos".

O artigo não deixa transparecer ao leitor que o trabalho dos cientistas é passível de erro, que pode ser refutado por outros cientistas, as medições podem sofrer interpretações equivocadas por parte do especialista. Independente do status excessivamente elevado creditado aos especialistas, o artigo traz um ponto bastante importante: ao expressar que governantes e cientistas possuem certa relação, e que o trabalho dos especialistas está voltado para tentar mitigar os efeitos das mudanças climáticas, o texto demonstra que o trabalho científico não acontece à margem da sociedade. Assim, o trabalho científico influencia no contexto social, ambiental, físico em que está inserido, como também, é influenciado por este meio a realizar seu trabalho e buscar soluções. O que Praia, Gil-Perez e Vilches (2007) colocam como caráter social do desenvolvimento científico.

Esse trecho do artigo QSO4 tem especial potencial para gerar uma discussão sobre um aspecto essencial da ciência: a não neutralidade da ciência e do pensamento científico, que pode ser entendida através da influência dos diversos contextos (social, político, cultural, etc.) no qual a ciência é construída, e, a influência dos diversos contextos (crenças, influencias sociais, etc.) sobre os cientistas no processo de construir os conhecimentos científicos. Nas palavras de Moura (2014), para aqueles que defendem uma visão sobre natureza da ciência no ensino através de 
características (aspectos consensuais), toda ideia científica ou cientista está envolto em concepções, questões de época, local em que vivem, influências que interferem na aceitação, rejeição e desenvolvimento do pensamento.

Não se pode afirmar que o texto tem a intenção de promover esse caráter social do desenvolvimento científico veiculando um tipo de relacionamento entre governantes e pesquisadores. Entretanto, deve-se levar em consideração o potencial de suscitar essa discussão no ambiente formal de ensino através de uma intervenção pedagógica atenta, crítica e contextualizada, a fim de evitar concepções equivocadas sobre ciência e sobre o trabalho do cientista por estudantes, já que isso pode ocorrer em diferentes níveis educacionais (AZEVEDO; SCARPA, 2017).

No artigo QSO7 que inicia apresentando alguns dados sobre a mudança de temperatura no planeta e esclarecendo de uma maneira bem próxima do público não especialista como a atividade solar acontece e influencia o planeta, é possível perceber menção aos procedimentos inerentes da atividade científica na construção do conhecimento no seguinte trecho: "Modelos sofisticados da temperatura global, ignorando qualquer intervenção humana, podem recriar os padrões observados até a década de 1950". De forma sucinta, sem apresentar discussões, o artigo utiliza os termos "modelos sofisticados" e "padrões observados" que pertencem ao contexto da atividade científica. E continua: "... depois disso, não conseguem explicar o que está a ocorrer. Ao contabilizar os efeitos das emissões humanas, porém, subitamente tudo bate certo". Observa-se, então, o caráter infalível creditado aos procedimentos da ciência.

O texto QS11 tem por título "Mais $\mathrm{CO}_{2}$ é bom porque as plantas precisam dele" e objetiva, segundo a revista, desmistificar o mito expresso em seu título. Traz uma explicação simples, correta e de fácil entendimento sobre o papel do dióxido de carbono na fotossíntese das plantas. No final o texto QS11 apresenta um procedimento (experiência) realizado por uma equipe de especialistas de uma universidade. Expõe o procedimento da seguinte maneira: "Duplicaram $\mathrm{O} \mathrm{CO}_{2}$, subiram a temperatura em um grau, e aumentaram a precipitação e o azoto no solo". No final, o texto traz o resultado que, nessa experiência, o crescimento vegetal estagnou. Os procedimentos mencionados encontram papel importante na construção da argumentação do artigo para tentar cumprir seu objetivo de desmitificar uma concepção expressa em seu título. Isso valoriza os procedimentos. Ainda assim, não há espaço para discussão sobre as condições da experiência. Ela é apresentada, por si só, como solução de questão, como se uma única experiência conduzida por um grupo de especialistas da mesma universidade pudesse derrubar o imaginário social.

Ora, de acordo com Vital e Guerra (2014), apesar da diversidade de concepções sobre a ciência que gera dificuldade em estabelecer um consenso absoluto sobre os pressupostos válidos, existem alguns pontos tidos como consensuais que podem e devem ser ensinados, dentre eles "a inexistência de um único método científico, universal e infalível" (VITAL; GUERRA, 2014, p. 230). Colocar uma única experiência, 
conforme os textos QSO7 e QS11 fazem, com esse caráter infalível e solucionador prejudica a construção de uma visão da ciência mais próxima da realidade.

Inclusive, em Cachapuz et al. (2011), vemos que o comportamento de apresentar uma informação de forma engessada, sem discussão e distante da realidade dinâmica da comunidade científica, que contribui para propagar uma visão distorcida do que venha ser ciência, está presente também no Ensino de Ciências. No ambiente escolar é necessário atenção quanto a isso para não promover uma visão distorcida da ciência aos estudantes. A intervenção do docente em levantar a discussão não colocada nos textos sobre os procedimentos se faz necessária para evitar propagar a ideia de uma experimentação neutra e ateórica.

Ainda assim, os artigos QS07e QS11 podem servir como ponto de partida para uma discussão sobre o método científico. Os artigos colocam, equivocadamente, a ideia de uma experimentação única, satisfatória e solucionadora. Com uma intervenção pedagógica perspicaz, é possível utilizar esse equívoco para se discutir uma visão sobre ciência mais adequada, especificamente, uma ciência que se baseia em diversos métodos, mas não em um único. Uma construção do conhecimento científico que se dá através do uso de variados métodos, destacando, conforme Moura (2014), a multiplicidade de formas como o trabalho científico é feito.

Na revista Superinteressante é possível observar em seu artigo SUP01, um comportamento diferente dos textos QSO4, QSO7 e QS11. No texto SUP01, em dois momentos são apresentadas informações que caracterizam procedimentos: no início do artigo, quando o autor descreve o fato que promove a mudança de perspectiva da comunidade mundial em relação ao ambiente: "Até que satélites identificaram que 50\% do ozônio sobre a Antártida havia desaparecido". Essa colocação apresenta, mesmo que de forma simplista, de onde vieram os dados que movimentaram a comunidade científica. E no final quando o autor traz um questionamento, ele justifica sua posição pautando-se em resultados obtidos através da modelagem matemática:

Se esse cenário é mais desolador, por que o sucesso de Montreal não se repetiu em Kyoto e no Rio? A grande diferença é que o buraco no ozônio foi observado. Já o aquecimento global é calculado por modelos matemáticos (até por isso os aumentos previstos na temperatura vêm com precisão em casas decimais, apesar das enormes margens de erro) (SUPERINTERESSANTE, 2012, p. 1).

É possível ver a importância dada pelo autor às informações, neste caso a aplicação de modelos matemáticos na previsão dos aumentos da temperatura global, para justificar sua posição face à pergunta levantada por ele próprio. Ainda assim, 0 autor não deixa de mencionar o caráter falível do procedimento.

Esse fato do autor mencionar que existe margem de erro no procedimento é importante, pois segundo Gomes, Silva e Machado (2016), a falsa imagem de que a 
ciência é infalível e solucionadora de todos os problemas ainda é criada por muitas pessoas, sobretudo estudantes.

Segarra et al. (2017), nesse contexto de imagem deformada sobre a ciência, afirmam que as distorções justificam, de certo modo, o fracasso dos estudantes e a rejeição à ciência por parte deles. $E$ concluem que, formalmente ou informalmente, a educação científica não pode ocorrer com visões simplistas e empobrecidas.

O combate a essa visão simplista da ciência passa pelo conhecimento do público não especializado de como funciona a ciência, das discussões na comunidade científica, dos percalços, dos acertos e erros, das controvérsias e procedimentos sujeitos a falha.

\section{FUNCIONAMENTO INSTITUCIONAL DA CIÊNCIA}

Nesta categoria, o intuito é analisar se os artigos apresentam alguma informação característica do âmbito da comunidade científica que estejam relacionadas ao conflito de ideias, divergências de opiniões, discussões inerentes ao funcionamento da ciência.

Esse tipo de informação é tão importante quanto a informação que retrata processos, procedimentos, materiais e métodos na construção do conhecimento científico para influenciar na propagação do que venha ser ciência. Portanto, qualquer informação que está relacionada ao contexto de discussão e controvérsia que pertence à comunidade científica, posicionamentos divergentes de especialistas, e, a visão do texto frente à discussão foi foco dessa categoria.

Tanto a Superinteressante quanto a Quero Saber apresentaram somente um artigo onde é possível observar elementos que contextualizam o funcionamento dinâmico da ciência aos seus leitores: SUPO4 e QS01. Nesses textos, encontram-se momentos de conflito, divergência e posicionamento contrário entre os especialistas.

Outra semelhança entre a revista brasileira e a revista portuguesa é que os demais artigos utilizam da fala (direta ou indireta) de especialistas, grupo de cientistas, instituições científicas, entre outros, mas apresenta uma visão única. Além disso, percebe-se que os textos, em sua maioria, recorrem a esse posicionamento único para conseguir respaldo em seus argumentos, o que nos permite dizer que a visão do artigo é homogênea (o autor (a) está de acordo com a fala dos especialistas).

Reis (2009) caracteriza a instituição científica como competitiva e conflituosa, marcada por conflitos sociais entre grupos de cientistas que buscam maior credibilidade de sua teoria frente a outros grupos. Essa característica pode ser observada no artigo SUPO4, mesmo que de maneira superficial. $\mathrm{O}$ artigo, ao trazer a informação de que existe uma significativa bolha de gás metano sob o gelo da Sibéria, cita uma afirmação de um grupo de especialistas: " $O$ problema é que, com 0 aquecimento global, o gelo da Sibéria está derretendo - e pode deixar o metano escapar para a atmosfera, onde ele provocaria um desastre ambiental". O decorrer do 
artigo, algumas consequências dessa afirmação são colocadas. Mais para o final do artigo, outro especialista é citado e sua fala colocada: "O gelo marinho derrete tanto, e fica assim por tanto tempo a cada verão, que a plataforma siberiana fica descoberta por um tempo substancial'. Até então não há divergências de ideias, e sim, duas conclusões numa mesma direção: chance do metano escapar e provocar um desastre ambiental. No final do artigo é mencionado que o estudo tem sido contestado por outros especialistas que não acreditam na liberação dessa bolha, estabelecendo, portanto, o conflito de posicionamento dentro da comunidade científica.

No artigo QSO1 que argumenta a capacidade humana de controlar o tempo através de tecnologias, a divergência de ideias dentro da comunidade científica é colocada ao leitor de forma explícita e clara. 0 texto traz esse contexto em diversos trechos. Por exemplo, quando fala sobre os meteorologistas chineses terem feito nevar em uma determinada região apresentando como foi realizada a técnica conhecida como inseminação das nuvens: "(...) milhões de toneladas de neve terão caído no norte da China, assolado pela seca, depois que operários dispararam foguetes com pequenas bolas de iodeto de prata". Nesse ponto em diante, o artigo apresenta argumentos dos defensores da técnica. Em seguida, é apresentada outra posição que contesta a eficácia dessa tecnologia: "Um estudo de 2003 das Academias Nacionais do EUA concluiu que não existe provas científicas concretas de seu resultado".

Em outro momento, o texto apresenta ideias da geoengenharia para modificar o clima em uma escala global e, mais uma vez, demonstra que pensamentos diferentes entre os especialistas são comuns. Enquanto americanos investem em inseminação de nuvens em tempestades de inverno acreditando ser a solução, "este tipo de nuvens são o alvo principal da inseminação. Muitas vezes não são suficientes a gerar neve $e$ a inseminação é usada para aumentar a produção", britânicos defendem que não são as técnicas que irão evitar o aquecimento em larga escala, e sim a redução da emissão de gás carbônico: " $A$ geoengenharia é essencialmente um 'Plano B' caso a redução da emissão de gases com efeito estufa seja insuficiente e realizada demasiado tarde para evitar alterações climáticas perigosas".

O artigo QSO1 não se posiciona diante do contexto de divergência ou, no mínimo, posicionamentos diferentes. A revista se mantém imparcial em seus argumentos. Limita-se em mencionar esse contexto quando se trata da tentativa de controlar o tempo por meio de tecnologias científicas. Não seria prudente afirmar que as divergências estão no contexto político, mesmo os grupos de especialistas pertencendo a nacionalidades diferentes (americanos divergindo de chineses, e britânicos divergindo de americanos). O texto não deixa claro isso. Entretanto, podemos afirmar que esse contexto está implícito, já que a nacionalidade dos cientistas é sempre mencionada. $O$ texto poderia colocar o posicionamento do cientista, apenas. Essa postura do texto, intencional ou não, contribui para influenciar uma visão de ciência mais próxima da realidade. De acordo com Moura (2014), demonstrar que a ciência é influenciada pelos contextos cultural, social, político, entre outros, evidencia que nenhuma ideia científica está blindada de concepções e questões da época, 
evidenciando assim a não neutralidade da ciência. Nesse sentido, através da demonstração de elementos que caracterizam o funcionamento institucional da ciência, este artigo proporciona uma concepção mais adequada do que seja ciência.

Levar ao leitor informações que contribuem para um melhor entendimento de como o conhecimento é construído, sob quais circunstâncias, que tipo de relacionamento há na comunidade científica, pode promover um sentimento de proximidade. Isso combate a visão deturpada de uma ciência individualista e elitista onde o conhecimento seria construído por indivíduos superdotados (gênios) e isolados (GIL-PEREZ et al., 2001).

Segundo Sheid, Ferrari e Delizoicov (2007), uma compreensão adequada sobre ciência envolve, entre outros aspectos, compreender como se constrói e se desenvolve o conhecimento, os valores (implícitos e/ou explícitos) nas atividades da comunidade científica e compreender seu funcionamento interno. Aqui se insere o ponto investigado nesta categoria: discussões no âmbito das ideias.

Calero, Vilches e Gil-Perez (2013) afirmam que é possível utilizar as informações midiáticas como recurso para contribuir na reflexão sobre os problemas socioambientais e na mudança de atitude, através da informação contextualizada. Essa contextualização está no sentido de permitir ao público ter contato com as circunstâncias que envolvem a dinâmica científica.

Sendo assim, apresentar e discutir a dinâmica científica (investigada neste trabalho através de procedimentos/materiais/instrumentos, e ideias/conflitos/divergências), é também oferecer ao leitor uma informação contextualizada com possiblidade de contribuir para o exercício da cidadania desse leitor.

\section{CONSIDERAÇõES FINAIS}

Bem verdade que a DC não tem função de ensinar ciência. Ao compartilhar o saber científico, a DC contribui para o desenvolvimento de uma reflexão crítica sobre a ciência quando leva em consideração o público não especialista (seu contexto, seus valores, aspectos culturais, perspectivas). Ou seja, quando se distancia de um relacionamento vertical de veiculação da informação - no sentido de cima (especialistas) para baixo (não especialistas) - procurando estabelecer diálogo entre cientistas e sociedade. Dito isso, esclarecemos que não podemos atribuir aos textos das revistas analisadas a responsabilidade do ensino de ciência, mas que possuem por sua própria natureza (são revistas que divulgam o conhecimento científico ao público geral) o potencial de servir como ponto de partida, complementação, reforço, para uma discussão sobre ciência.

A contribuição da DC excede o papel de apenas informar, quando assume uma postura crítica, competente, contextualizada e analítica sobre os efeitos (riscos e benefícios) da política e de produção das pesquisas científicas (CARNEIRO, 2014). Essa 
postura da DC pode contribuir para a retirada do indivíduo de um estado de passividade para o estado de reflexividade através de um trabalho coletivo de reflexão.

As revistas de DC, como a Superinteressante e a Quero Saber, encontram fatores que corroboram para uma divulgação eficiente, contextualizada, que sobressai a outros meios impressos. Ao analisar as revistas, encontramos fatores que estão alinhados com a literatura, dentre eles, destacamos a possibilidade de uma linguagem mais aprofundada nos conteúdos (CARVALHO, 2011; DIAS; ALMEIDA, 2009; GRILLO, 2013), a estética - acabamento gráfico, ilustrações, entre outros - (MORAES, 2007) e linguagem próxima ao público não especialista. Ainda assim, exige atenção e articulação por parte dos educadores quando utilizam o texto das revistas no ensino de ciências.

As revistas analisadas têm um bom uso dos recursos de escrita e imagem (figuras, infográficos, esquemas, box) dando um caráter dinâmico e didático aos seus artigos. A proposta de informar o leitor sobre assuntos diversos, talvez possa justificar o empenho das revistas em informar respaldando-se em dados científicos. Entretanto, a falta de discussão sobre a natureza desses dados (obtenção, análise, elaboração) e a reprodução unilateral da informação (não evidenciar posicionamento contrário por outras fontes) pode afastar o público da realidade da atividade científica.

Distanciar do público as circunstâncias que cercam a construção do saber científico corrobora para uma visão distorcida do que venha a ser ciência. Nesse sentido, suprimir os procedimentos internos da ciência (elaboração, aplicação e adequação de modelos, os caminhos tomados para se chegar aos resultados obtidos pela fonte da informação, o papel da experimentação, os procedimentos de análise e inferência dos dados, etc.) e o funcionamento institucional da ciência (controvérsias científicas, a diversidade de ideias, os conflitos de pesquisadores, a relação entre o processo da ciência e seu produto, etc.) fortalece esse tipo de visão.

Percebe-se pelos artigos analisados que trazer os procedimentos científicos como mais um elemento na construção da argumentação do artigo pode contribuir para o reforço de uma visão simplista. Desse modo, a problematização da informação por parte do divulgador traz uma proximidade mais condizente com a realidade. Em um ambiente de ensino formal, a problematização da informação dos artigos por parte do docente trazendo a discussão que falta nos artigos é essencial para evitar uma visão distorcida, simplista, distante da realidade e ingênua.

A falta de elementos que demonstrem a dinâmica científica (aqui representada pelas categorias analisadas) em alguns textos das revistas investigadas não indica que o material não possa ser utilizado, mas será preciso, conforme aponta Faria et al. (2014), confrontar e clarificar explicitamente, as imagens estereotipadas acerca da ciência e da atividade científica.

Este artigo procurou contribuir para a discussão de como as revistas de DC podem influenciar na construção de uma visão sobre a ciência pelo público não especialista, especificamente, através da apresentação ou não de informações que 
retratam a atividade científica. Espera-se que novas pesquisas sejam realizadas a fim de enriquecer análises específicas sobre a maneira com que as revistas de DC, em seus diversos contextos culturais, têm realizado seu trabalho, inferindo sobre o seu potencial social e de ensino.

\section{REFERÊNCIAS}

ALBAGLI, S. Divulgação científica: informação científica para a cidadania? Ciência da Informação, v. 25, n. 3, p. 396-404, 1996.

AZEVEDO, N. H.; SCARPA, D. L. Revisão Sistemática de Trabalhos sobre Concepções de Natureza da Ciência no Ensino de Ciências. RBPEC, v. 17, n. 2, 2017. p. 579-619.

BARDIN, L. Análise de Conteúdo. Lisboa: Edições, 2002.

CACHAPUZ, A.; GIL-PÉREZ, D.; CARVAlHO, A. M. P.; PRAIA, J.; VILCHES, A. $A$ necessária renovação do Ensino das Ciências. São Paulo: Cortez, 2011.

CALERO, M.; VILCHES, A.; GIL-PEREZ, D. Necesidad de la Transición a la Sostenibilidad: papel de los medios de comunicación en la formación ciudadana. Didáctica de las Ciencias Experimentales y Sociales. n. 27, 2013. p. 235-254.

CARNEIRO, C. D. R.; TONIOLO, J. C. A Terra 'quente' na imprensa: confiabilidade de notícias sobre aquecimento global. História, Ciências, Saúde - Manguinhos, v. 19, n. 2, 2012. p. 369-389.

CARNEIRO, D. L. C. M. Divulgação Científica: as representações sociais de pesquisadores brasileiros que atuam no campo da Astronomia. 2014. Tese (Doutorado em Educação) - Universidade Federal de Uberlândia/UFU, Uberlândia, MG, Brasil, 2014.

CARVALHO, C. P. Divulgação científica nas revistas Ciência Hoje, Scientific American Brasil e Superinteressante: estudo comparativo. Tese (Doutorado em Comunicação) UMESP, São Bernardo do Campo, SP, Brasil, 2011.

CARVALHO, I. L. A.; ROCHA, M. B. Análise de metáforas e analogias em reportagens sobre mudanças climáticas na revista Superinteressante. In: V Encontro Nacional de Ensino de Ciências da Saúde e do Ambiente. Caderno de Resumos. Niterói: UFF, p.52, Maio, 2018.

DIAS, R. H. A.; ALMEIDA, M. J. P. M. de. Especificidades do jornalismo científico na leitura de textos de divulgação científica por estudantes de licenciatura em física. Revista Brasileira de Ensino de Física, v. 31, n. 4, 4401, 2009. 
FARIA, C.; FREIRE, S.; GALVÃO, C.; REIS, P.; FIGUEIREDO, O. "Como trabalham os cientistas?": potencialidades de uma atividade de escrita para a discussão acerca da natureza da ciência nas aulas de ciências. Ciência \& Educação, v. 20, n. 1, 2014. p. 122.

FRAGA, F. B. F. F.; ROSA, R. T. D. Microbiologia na revista Ciência Hoje das Crianças: análise de textos de divulgação científica. Ciência \& Educação (Bauru), v. 21, n. 1, 2015. p. 199-218.

GADEA, I.; SEGARRA, A.; VILCHES, A.; GIL PÉREZ, D. Contribución de la prensa a la Educación Científica y Tecnológica. Enseñanza de Las Ciencias, n. ${ }^{\circ}$ Extraordinario, 2017. p. $1567-1572$.

GIL PÉREZ, D.; MONTORO, I. F.; ALÍS, J. C.; CACHAPUZ, A.; PRAIA, J. Para uma imagem não deformada do trabalho científico. Ciência \& Educação, v. 7, n. 2, 2001. p. 125-153.

GODOY, A. S. Pesquisa qualitativa: tipos fundamentais. Revista de Administração de empresas, v. 35, n. 3, 1995. p. 20-29.

GOMES, I. A. A divulgação científica em Ciência Hoje: características discursivo textuais. Tese de Doutorado. Tese (Doutorado em Linguística), Universidade Federal de Pernambuco, Recife, 2000.

GOMES, V. B.; SILVA, R. R.; MACHADO, P. F. L. Elaboração de textos de divulgação científica e sua avaliação por alunos de Licenciatura em Química. Química Nova na Escola (Cadernos de Pesquisa), v. 38, n. 4, 2016. p. 387-403.

GRILLO, S. V. C. Divulgação Científica: linguagens, esferas e gêneros. Tese (livredocência), USP - São Paulo, SP, 2013.

LEITE, J. C. Controvérsias na climatologia: o IPCC e o aquecimento global antropogênico. Scientiae Studia, v. 13, n. 3, 2015. p. 643-677.

LIMA, G. S.; GIORDAN, M. Propósitos da Divulgação Científica no Planejamento de Ensino. Revista Ensaio (Belo Horizonte), n. 19, 2017. p. 1-23.

LOOSE, E. B; GIRARDI, I. M. T. A segmentação das revistas e a temática ambiental. Rev. Estud. Comun., Curitiba, v. 10, n. 22, 2009. p. 129-137.

LÜDKE, M.; ANDRÉ, M. E. D. A. Pesquisa em educação: abordagens qualitativas. São Paulo: EPU, 1986. 
MARTINS, A. F. P. Natureza da Ciência no ensino de ciências: uma proposta baseada em "temas" e "questões". Caderno Brasileiro de Ensino de Física, v. 32, n. 3, 2015. p. 703-737.

MCCOMAS, W. F. (Ed.) The nature of science in science education: rationales and strategies. New York: Kluwer Academic Publishers. 1998.

MONERAT, C, A. A.; ROCHA, M. B. Como as revistas de Divulgação Científica utilizam os recursos imagéticos em textos sobre Biologia Celular. Acta Scientiae, v. 19, n. 6, 2017.

MORAES, V. R. F. Jornalismo científico fetichizado: análise comparativa das revistas Superinteressante, suas edições especiais e National Geographic Magazine. 2007. Dissertação (Mestrado em Ciências Sociais), UNESP - São Paulo, 2007.

MOURA, B. A. O que é natureza da Ciência e qual sua relação com a História e Filosofia da Ciência? Revista Brasileira de História da Ciência, Rio de Janeiro, v. 7, n. 1, 2014. p. 32-46.

PECHULA, M. R. A ciência nos meios de comunicação de massa: divulgação de conhecimento ou reforço do imaginário social? Ciência e Educação, v. 13, n. 2, 2007. p. 211-222.

PRAIA, J.; GIL-PÉREZ, D.; VILCHES, A. O papel da natureza da ciência na educação para a cidadania. The role of the Nature of Science in citizens' education. Ciência \& Educação, v. 13, n. 2, 2007. p. 141-156.

REIS, P. R. Ciência e Controvérsia. REU-Revistas de Estudos Universitários, v. 35, n. 2, 2009. p. 9-15.

ROCHA, M. B. Contribuições da divulgação científica na formação ambiental de estudantes da educação básica. Trilhas Pedagógicas, v. 7, n. 7, p. 172-184, Ago. 2017.

SCHEID, N. M. J.; FERRARI, N.; DELIZOICOV, D. Concepções sobre a natureza da ciência num curso de Ciências Biológicas: imagens que dificultam a educação científica. Investigações em Ensino de Ciências, v. 12, n. 2, 2007. p. 157-181.

SEGARRA, A.; GADEA, I.; VILCHES, A.; GIL-PÉREZ, D. Uso de los museos para contribuir a superar las visiones deformadas de la ciencia. Enseñanza de las ciencias: revista de investigación y experiencias didácticas, n. Extra, 2017. p. 3827-3832.

SULAIMAN, S.N. Educação ambiental, sustentabilidade e ciência: o papel da mídia na difusão de conhecimentos científicos. Ciência \& Educação, v. 17, n. 3, 2011. p. 645662. 
VALÉRIO, M.; BAZZO, W. A. O papel da divulgação científica em nossa sociedade de risco: em prol de uma nova ordem de relações entre ciência, tecnologia e sociedade. Revista de Ensino de Engenharia, v. 25, n. 1, 2006. p. 31-39.

VITAL, A.; GUERRA, A. A natureza da ciência no ensino de Física: estratégias didáticas elaboradas por professores egressos do mestrado profissional. Caderno Brasileiro de Ensino de Física, v. 31, n. 2, 2014. p. 225-257.

Recebido em 19 de julho de 2019.

Aceito em 28 de agosto de 2019.

A e-Mosaicos Revista Multidisciplinar de Ensino, Pesquisa, Extensão e Cultura do Instituto de Aplicação Fernando Rodrigues da Silveira (CAp-UERJ) está licenciada com uma Licença Creative Commons - Atribuição-NãoComercial 4.0 Internacional.

Os direitos autorais de todos os trabalhos publicados na revista pertencem ao(s) seu(s) autor(es) e coautor(es), com o direito de primeira publicação cedido à e-Mosaicos.

Os artigos publicados são de acesso público, de uso gratuito, com atribuição de autoria obrigatória, para aplicações de finalidade educacional e não-comercial, de acordo com o modelo de licenciamento Creative Commons adotado pela revista. 